\title{
Canalis mandibulae bifidus en trifidus. Een toevalsbevinding
}

Een 26-jarige man had pericoronitis van de derde molaren in de onderkaak. Om de positie van de canalis mandibulae ten opzichte van de wortels van de derde molaren te beoordelen, werd een panoramische röntgenopname gemaakt. Hierop werd een canalis mandibulae bifidus aan de rechterzijde gezien. Het bovenste deel van de canalis leek een relatie met de apices van gebitselement 48 te vertonen. Op een aanvullende cone beam-computertomogram werd aan de rechterzijde een canalis mandibulae trifidus gezien en aan de linkerzijde een canalis mandibulae bifidus. Een anatomisch afwijkend verloop van de canalis mandibulae kan klinische consequenties hebben, zoals een verhoogde kans op letsel van de nervus alveolaris inferior bij het verwijderen van de derde molaar of een onvolledig werkende lokale anesthesie.

Mizbah K, Gerlach N, Maal TJ, Bergé SJ, Meijer GJ. Canalis mandibulae bifidus en trifidus. Een toevalsbevinding

Ned Tijdschr Tandheelkd 2010; 117: 616-618

doi:10.5177/ntvt.2010.12.10155

\section{Gegeven}

Een gezonde man van 26 jaar werd door zijn tandarts verwezen naar een mond-, kaak- en aangezichtchirurg voor de verwijdering van de derde molaren in de onderkaak in verband met pijnklachten.

\section{Anamnese}

De patiënt had nog niet eerder pijnklachten gehad, had geen koorts, had een blanco voorgeschiedenis en gebruikte geen medicamenten.

\section{Diagnostiek}

Bij intraoraal onderzoek bleek sprake van pericoronitis van de partieel geërupteerde derde molaren in de onderkaak. Op de vervaardigde panoramische röntgenopname werd bij beoordeling aan de rechterzijde een dubbelsporige canalis mandibulae, een canalis mandibulae bifidus, vermoed (afb. 1). Dit vermoeden werd bevestigd op de sagittale en coronale doorsneden van het aanvullend vervaardigde cone beam-computertomogram (cone-beam CT) (afb. 2). Als toevalsbevinding werd beiderzijds nog een extra kanaal gezien. Dit betekent dat aan de rechterzijde een driesporige canalis, canalis mandibulae trifidus, aanwezig was en aan de linkerzijde een canalis mandibulae bifidus. De niet zichtbare aftakkingen lieten op de panoramische röntgenopname een achterwaarts verloop zien, in de richting van de retromolaarregio (afb. 3).

\section{Behandeling}

$\mathrm{Na}$ 'informed consent' werden beide derde molaren chirurgisch verwijderd. De afwijkende anatomie van de canalis

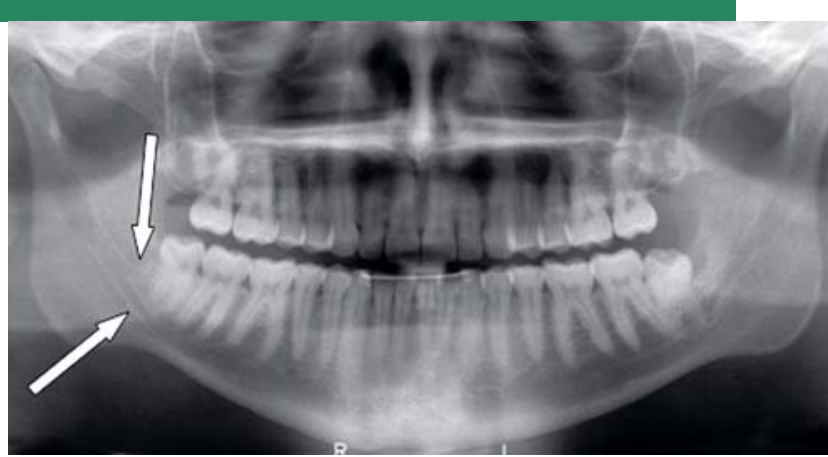

Afb. 1. Panoramische röntgenopname suggestief voor de aanwezigheid van een splitsing van de canalis mandibulae aan de rechterzijde.

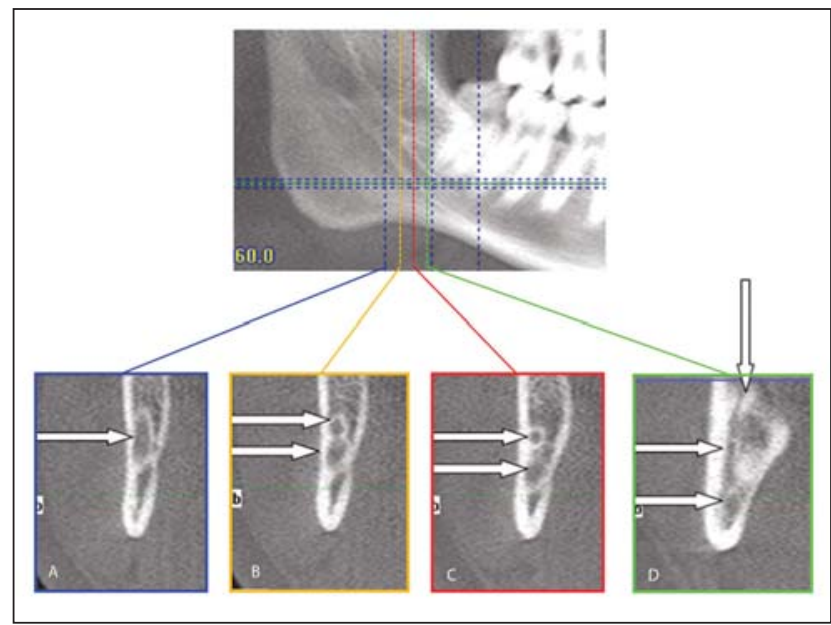

Afb. 2. Opeenvolgende coronale doorsneden.

a. De canalis voor de splitsing.

b. De canalis tijdens de splitsing.

c. Dubbelsporige canalis,

d. Retromolare aftakking die overlangs is aangesneden.

mandibulae dicteerde de wijze van chirurgische behandeling; vanwege de proximiteit van de canalis werd distaal van de molaar niet afgeschoven. Eerst werd met behulp van een fissuurboor de kroon verwijderd. Hierna vond verticale splitsing van de radices plaats, waarna met een smalle hevel de mesiale en distale wortel separaat konden worden verwijderd. Postoperatief werden geen sensibiliteitsveranderingen vastgesteld.

\section{Beschouwing}

Over anatomische variaties van de canalis mandibulae is een aantal casussen gerapporteerd (Kaufman et al, 2000; Dario, 2002; Auluck en Pai, 2005; Claeys en Wackens, 2005). Uit onderzoeken bij groepen patiënten en van onderkaken van kadavers bleek de incidentie tussen de 0,1 en 17\% te liggen (tab. 1) (Nortjé et al, 1977; Durst en Snow, 


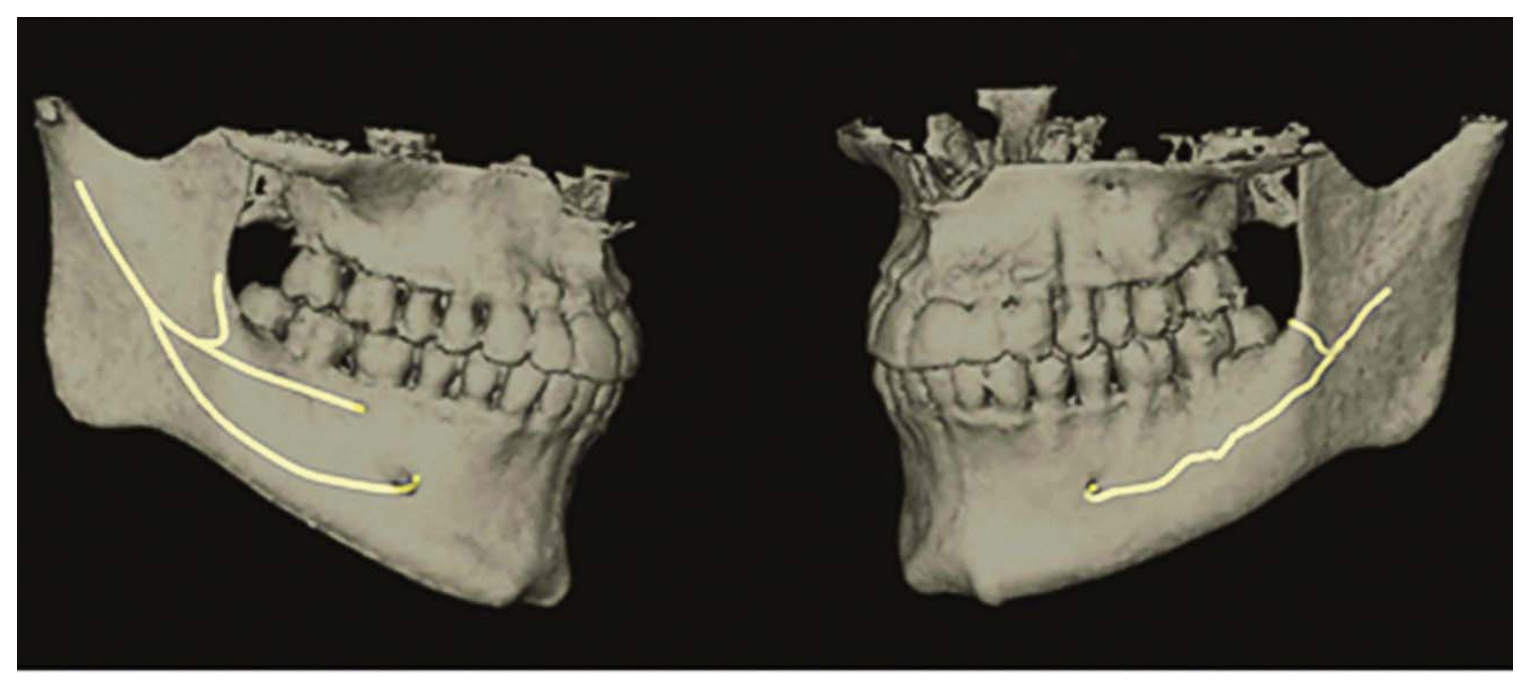

Afb. 3. Reconstructiebeeld waarbij de canalis mandibulae bifidus en trifidus zichtbaar zijn gemaakt.

1980; Grover en Lorton, 1983; Lanlais et al, 1985; Sanchis et al, 2003; Bogdán et al, 2006). De eerst gerapporteerde canalis mandibulae trifidus was uitsluitend gebaseerd op een conventionele panoramische röntgenopname, maar men verifieerde de bevinding niet met een cone beam-CT (Auluck en Pai, 2005). Dat is echter wel noodzakelijk omdat sprake kan zijn van een verkeerde interpretatie. Zo kan een impressie van de nervus mylohyoideus in de mediale cortex van de onderkaak waar deze zich afsplitst van de nervus alveolaris inferior eveneens het beeld van een extra kanaal simuleren (Wilson et al, 1984). De eerst geobjectiveerde diagnose van een canalis mandibulae trifidus werd gepresenteerd in een onderzoek bij een kadaver (Bogdán et al, 2006).

In de kleinere kanalen zullen alleen vaten verlopen, terwijl de grotere kanalen naast vaten ook zenuwweefsel zullen omvatten (Bogdán et al, 2006). Dit laatste zal vooral het geval zijn als het extra kanaal, zoals in deze casus, een evidente afsplitsing van de hoofdtak is. Histologisch werd de aanwezigheid van zenuwweefsel in zo'n canalis mandibulae trifidus eerder bevestigd (Bilecenoglu et al, 2006).

\section{Discussie}

Sparen van de nervus alveolaris inferior bij chirurgische behandelingen in de onderkaak is een belangrijke uitdaging. Zo is bij het verwijderen van een derde molaar een betrouw-

\begin{tabular}{|l|l|r|r|}
\hline Referentie & Aantal patiënten & \multicolumn{1}{c|}{ Bifidus } & Trifidus \\
\hline Nortjé et al, 1977 & 3.612 patiënten & $1,0 \%$ & $0 \%$ \\
Durst en Snow, 1980 & 1.024 patiënten & $8,0 \%$ & $0 \%$ \\
Grover en Lorton, 1983 & 5.000 patiënten & $0,1 \%$ & $0 \%$ \\
Lanlais et al, 1985 & 6.000 patiënten & $1,0 \%$ & $0 \%$ \\
Sanchis et al, 2003 & 2.012 patiënten & $0,4 \%$ & $0 \%$ \\
Bogdán et al, 2006 & Kadaveronderzoek & $17,0 \%$ & $2 \%$ \\
& 46 onderkaken en & & \\
& 1.000 patiënten & & \\
\hline
\end{tabular}

Tabel 1. Gerapporteerde incidenties van op een panoramische röntgenopname waargenomen canalismandibulae bifidus en trifidus in diverse onderzoeken. baar inzicht in de driedimensionale relatie van de apices ten opzichte van de canalis mandibulae essentieel om compressie op de nervus alveolaris inferior te voorkomen. Ook tijdens het prepareren van een implantaatschacht kan de nervus alveolaris inferior worden getraumatiseerd. Een goede diagnostiek is daarom van eminent belang.

Het is gebruikelijk voor aanvang van een chirurgische behandeling in de onderkaak een panoramische röntgenopname te vervaardigen. Deze geeft slechts tweedimensionale beelden. Ondanks deze beperking van de panoramische röntgenopname kunnen anatomische variaties van de canalis mandibulae op grond van het verkregen beeld vaak worden vermoed en aansluitend worden opgespoord (Vasquez et al, 2008). Een driedimensionale weergave heeft echter als groot voordeel dat ook de buccolinguale positie van de canalis mandibulae nauwkeurig kan worden vastgesteld. Conventionele computertomografie maakt driedimensionaal inzicht wel mogelijk, maar heeft als grote nadelen ten opzichte van de panoramische röntgenopname een hogere stralingsbelasting en de hogere kosten (Schulze et al, 2004). De onlangs geïntroduceerde cone beam-CT is ten opzichte van de conventionele computertomografie goedkoper, heeft een lagere stralingsbelasting en biedt een grotere ruimtelijke resolutie (Ludlow et al, 2006; Boeddinghaus en Whyte, 2008). Hierdoor wordt het mogelijk, indien nodig, aanvullende diagnostiek te verrichten naar de anatomische variaties van de canalis mandibulae. Bij de behandeling kan hiermee dan rekening worden gehouden.

Variaties in het anatomische verloop van de canalis mandibulae, zoals een canalis mandibulae bifidus of trifidus hebben belangrijke klinische implicaties, bijvoorbeeld als verklaring voor een insufficiënte geleidingsanesthesie van de nervus alveolaris inferior, vooral in aanwezigheid van 2 mandibulaire foramina (Grover et al, 1983). Beschadiging van een tweede of zelfs derde neurovasculaire bundel kan complicaties veroorzaken, zoals een sensibiliteitsstoornis, een neuroom of een bloeding. 


\section{Leermoment}

Controle op aanwezigheid van een canalis mandibulae bifidus of trifidus kan worden uitgevoerd door middel van een conventionele panoramische röntgenopname. In geval van een positieve bevinding kan bij een geplande chirurgische behandeling in de onderkaak een aanvullende cone beam-CT extra informatie verschaffen.

\section{Literatuur}

* Auluck A, Pai KM. Trifid mandibular nerve canal. Dentomaxillofac Radiol 2005; 34: 259

* Boeddinghaus $R$, Whyte A. Current concepts in maxillofacial imaging. Eur J Radiol 2008; 66: 396-418.

* Bilecenoglu B, Tuncer $N$. Clinical and anatomical study of retromolar foramen and canal. J Oral Maxillofac Surg 2006; 64: 1493-1497.

* Bogdán S, Pataky L, Barabás J, Németh Z, Huszár T, Szabó G. Atypical courses of the mandibular canal: comparative examination of dry mandibles and x-rays. J Craniofac Surg 2006; 17: 487-491.

* Claeys V, Wackens G. Bifid mandibular canal: literature review and case report. Dentomaxillofac Radiol 2005; 34: 55-58.

* Dario LJ. Implant placement above a bifurcated mandibular canal: a case report. Implant Dent 2002; 11: 258-261.

* Durst JH, Snow JE. Multiple mandibular canals: oddities or fairly common anomalies. Oral Surg Oral Med Oral Pathol 1980; 49: 272- 273

* Grover PS, Lorton L. Bifid mandibular nerve as a possible cause of inadequate anesthesia in the mandible. J Oral Maxillofac Surg 1983; 41: 177-179.

* Kaufman E, Serman NJ, Wang PD. Bilateral mandibular accessory foramina and canals: a case report and review of the literature. Dentomaxillofac Radiol 2000; 29: 170-175.

* Langlais RP, Broadus R, Glass BJ. Bifid mandibular canals in panoramic radiographs. J Am Dent Assoc 1985; 110: 923-926.

* Ludlow JB, Davies-Ludlow LE, Brooks SL, Howerton WB. Dosimetry of 3 CBCT devices for oral and maxillofacial radiology: CB Mercuray, NewTom 3G and i-CAT. Dentomaxillofac Radiol 2006; 35: 219-226.

* Nortjé CJ, Farman AG, Grotepass FW. Variations in the normal anatomy of the inferior dental (mandibular) canal: a retrospective study of panoramic radiographs from 3.612 routine dental patients. Br J Oral Surg 1977; 15: 55-63.

* Sanchis JM, Peñarrocha M, Soler F. Bifid mandibular canal. J Oral Maxillofac Surg 2003; 61: 422-424.

* Schulze D, Heiland M, Thurmann H, Adam G. Radiation exposure during midfacial imaging using 4-and 16-slice computed tomography, cone beam computed tomography systems and conventional radiography. Dentomaxillofac Radiol 2004; 33: 83-86.

* Vasquez L, Saulacic N, Belser U, Bernard JP. Efficacy of panoramic radiographs in the preoperative planning of posterior mandibular implants: a prospective clinical study of 1.527 consecutively treated patients. Clin Oral Implants Res 2008; 19: 81-85.

* Wilson S, Johns P, Fuller PM. The inferior alveolar and mylohyoid nerves: an anatomic study and relationship to local anesthesia of the anterior mandibulair teeth. J Am Dent Assoc 1984; 108: 350-352.
Summary

Bifid and trifid mandibular canal. A coincidental finding

A 26-year-old man was suffering from pericoronitis of his mandibular third molars. To determine the position of the mandibular canal in relation to the roots of the third molars, a panoramic radiograph was made. The radiograph revealed at the right side a bifid mandibular canal and the upper part of the canal seemed to be related to the third molar. Additionally, a cone beam CT was made, which revealed a bifid mandibular canal at the left side and a trifid mandibular canal at the right side. Anatomical anomalies of the mandibular canal may have clinical implications, such as an increased risk of injury to the inferior alveolar nerve in case of removing a mandibular third molar and inadequate local anesthetics.

\section{Bron}

K. Mizbah, N. Gerlach, T.J. Maal, S.J. Bergé, G.J. Meijer

Uit de afdeling Mondziekten-, Kaak- en Aangezichtschirurgie, Universitair Medisch Centrum St Radboud te Nijmegen

Datum van acceptatie: 1 november 2010

Adres: prof. dr. G.J. Meijer, UMC St Radboud, Postbus 9101, huispost 590, 6500 HB Nijmegen

g.meijer@dent.umcn.nl 